Revista Monografias Ambientais - REMOA v. 15, n.1, Jan-Abr. 2016, p.01-05

Revista do Centro de Ciências Naturais e Exatas - UFSM, Santa Maria

\title{
A EDUCAÇÃO AMBIENTAL PARA ALÉM DO DESENVOLVIMENTO SUSTENTÁVEL
}

\author{
Environmental Education beyond Sustainable Development \\ Endell Menezes de Oliveira ${ }^{1}$ \\ 1Universidade da Amazônia.
}

\begin{abstract}
Resumo
O presente artigo discorre os perpasses da educação ambiental na formação do desenvolvimento sustentável e seus paradigmas. Designa um panorama entre a relação homem-sociedade-natureza, transcorrendo sobre a atomização do conhecimento em disciplinas, e como essa analogia prejudica a holística de visão da natureza como um todo. Observando, que a educação ambiental encontra-se em um campo de disputa, e que o termo desenvolvimento sustentável, torna-se errôneo e equívoco, na medida em que seu pressuposto mantém o status quo da sociedade, causando discriminação, abusos e acumulação de riquezas.
\end{abstract}

Palavras-chave: Educação Ambiental, Desenvolvimento Sustentável, Sociedade.

\section{Abstract}

This article discusses the perpasses of environmental education in the formation of sustainable development and its paradigms. Designates an overview of the human-society-nature relationship, spending on the atomization of knowledge into disciplines, and how this analogy affects the holistic view of nature as a whole. Noting that environmental education is in the playing field, and that the term sustainable development, it is wrong and mistake, in that its assumptions maintains the status quo of society, causing discrimination, abuse and accumulation of wealth.

Keywords: Environmental Education, Sustainable Development, Society. 


\section{INTRODUÇÃO}

A sociedade contemporânea vigente é reflexo da degradação ambiental, assumindo o caráter capitalista, e este, promovendo a transformação de uma sociedade com mercado, para uma sociedade de mercado, tendo assim, seu viés na acumulação de capital, na degradação dos ecossistemas, na mercantilização da natureza e nas desigualdades socioambientais. Como forma de mudança ou mitigação dos problemas ambientais (sejam eles de caráter social, político, ecológico, espacial ou histórico-cultural) vigorantes, surge o termo desenvolvimento sustentável, que a partir de ações e metodologias visa certos valores e princípios ambientais, como a conservação e o uso prudente dos recursos naturais e humanos para as gerações futuras. A Educação Ambiental aparece como peça chave neste processo, no diálogo entre possíveis soluções e os atores sociais que serão cobertos, ou não, por estas medidas.

Este trabalho apresenta os perpasses da educação ambiental no desenvolvimento sustentável diante a crise contemporânea, dialogando com suas ideologias, influências e direcionalidades. Além de, designar um panorama entre a relação homem-sociedadenatureza, decorrendo sobre a atomização do conhecimento em disciplinas, e como essa analogia prejudica a holística de visão da natureza como um todo. Tendo um efeito "cascata" na criação de paradigmas preconceituosos, exploratórios e que beneficiam uma pequena parte, privilegiada, da população.

\section{DESENVOLVIMENTO SUSTENTÁVEL E EDUCAÇÃO AMBIENTAL}

De acordo com Costa (2013, p. 303), a noção de desenvolvimento sustentável é, por outra parte, um ideário que emerge, se legitima e fortalece frente a uma realidade em crise, com manifestações claras de insustentabilidade. A construção do paradigma ambientalista é resultado de uma longa reflexão sobre as raízes éticas e ideológicas da crise ambiental que põe em cheque diretamente o modelo de desenvolvimento capitalista, questiona o lugar da espécie humana na natureza e a sua reponsabilidade pelo futuro da biosfera. (LIMA; POZZOBON. 2009, p. 197). Lima e Pozzobon (2009, p. 196) reforçam ainda, que uma sustentabilidade ecológica entende-se a capacidade de uma dada população de ocupar uma determinada área, com prudência sem prejudicar os recursos naturais, ao longo do tempo.

Dal Soglio (2013, p. 222) discorre que vivemos uma crise sistêmica, planetária, e os problemas se acumulam enquanto vemos que a solução dessa crise está sendo esperada dentro do mesmo paradigma que a gerou. Ou seja, a ideologia do desenvolvimento sustentável vem sendo constituída dentro dos limites da economia de mercado, oferecendo, portanto, soluções de mercado à crise ecológica. Desta forma, acaba-se privilegiando a construção de indicadores aparentemente alternativos, fortemente atrelados à mesma lógica de internalizar as implicações do mercado. Resultado de uma economia neoliberal, e de uma herança científica cartesiana, defendida pelos segmentos dominantes da sociedade, que causa a atomização do conhecimento em disciplinas, por isso, longe de resultados totalitários. As ideias associadas a esse modelo de desenvolvimento são a da modernização e progresso, que creem e professam um caminho evolutivo a seguir, tendo como referencial de sociedade "desenvolvida" aquelas que estão no centro do sistema capitalista, modelo hoje hegemônico em toda a parte do mundo com fim da bipolaridade, ou seja, o grupo daqueles países ditos do norte. (GUIMARÃES, 2009, p. 23). Precisa-se alterar profundamente a forma de se pensar, de enxergar a realidade, saindo 
de uma perspectiva cartesiana, que entende que as dimensões do sistema podem ser tratadas por disciplinas isoladas, e adotando um enfoque sistêmico. (DAL SOGLIO, 2013, p. 197). Lindner (2012, p.16) ressalta que, aprendemos muito sobre assuntos específicos e não sabemos relacioná-los a um contexto global sistêmico. O conceito de desenvolvimento sustentável, embora ambíguo e dotado de polissemia, coloca-nos à frente de um ideal de adaptação consciente. (LIMA; POZZOBON, 2009, p. 200). Portanto, Guimarães (2009, p.97) diz que para uma visão radical de sustentabilidade das relações ser humano-sociedade-natureza reconhecer o movimento do e das partes, em suas interações constitutivas de uma realidade complexa, requer outra estrutura de pensamento (paradigma).

Estas controvérsias colocam a noção sustentabilidade em um campo de disputa, as discussões acerca das relações que devem prevalecer entre o que deve ser sustentado e o que deve ser desenvolvido diferem muito, uma vez que essas interligações têm sido discutidas e consideradas de várias maneiras, dependendo por quem e em que esfera estão sendo discutidas, estabelecidas, ou implícitas. Camargo (2003) aponta algumas dessas divergências:

A Educação ambiental para além do desenvolvimento sustentável

“O que é, exatamente, o desenvolvimento sustentável? Que tipo de desenvolvimento se pretende? Que se deve sustentar? Que se deve desenvolver? Como podemos hoje considerar as necessidades das futuras gerações? Quais as decisões que, tomadas hoje, não prejudicarão as futuras gerações? Em que medida a utilização dos recursos deve ser contida hoje se desejarmos tutelar $o$ desenvolvimento no futuro? Quem seria realmente beneficiado nas gerações futuras: a maioria da população ou apenas poucos privilegiados? Qual a extensão de futuro a ser considerado?" (p. 78)

Diante a esse conflitos de paradigmas a educação ambiental se encontra, que no sistema atual está no campo das ações paliativas e pouco eficazes do ponto de vista de uma crítica radical ao modelo de desenvolvimento atual. Em oposto a Lindner (2012, p.15) quando descreve que o sistema educacional deve buscar ações e estratégias para que pessoas entendam às relações atuais de produção e consumo, bem como as futuras implicações, decorrentes da continuidade da utilização dos recursos naturais até a exaustão. Perpassando Guimarães (1996, p.95), que articula que a educação ambiental crítica volta-se para uma busca de uma sustentabilidade calcada em novos paradigmas. 


\title{
3 CONCLUSÃO
}

É necessário partir de uma sociedade humana diferenciada, conflitiva, que interage com seu entorno, a partir de classes e grupos em aliança e em oposição, com possibilidades e interesses diferentes e muitas vezes congruentes. (GUIMARÃES. 2009, p. 102). Debater e repensar valores para que sociedades sejam sustentáveis, social e economicamente, são missões inadiáveis que os professores e formadores de opinião precisam assumir. (LINDNER, 2012, p.17). Entendidos como interlocutores do conhecimento científico e produtores de conhecimento, a fim de que subsidiem práticas críticas sobre discursos hegemônicos. (GUIMARÃES, 2009, p. 81). Não como uma disciplina a ser inserida nos currículos escolares e que pode se perder em mais um dos compartimentos de nossa prática cartesiana. (LINDNER, 2012, p.15).

\begin{abstract}
“Educação para o desenvolvimento sustentável se mostra irrelevante e inapropriada, se não teremos que aceitar que a educação é o meio apenas de garantia da coesão e da convivência social, preparando melhor os indivíduos para exercerem suas funções em sociedade. Este perde qualquer sentido de formação humana, de prática emancipatória e se resume a meio ideológico de reprodução das sociedades de classes, de naturalização das relações sociais vigentes, pautadas na expropriação, na dominação e no preconceito." (LOUREIRO, 2014).
\end{abstract}

Deste modo, critica-se a noção de desenvolvimento sustentável em construção, porque se fundamenta nos paradigmas que consolidam esse modelo desenvolvimentista de sociedade que produziu a atual crise ambiental, modelo que se pretende propagar (GUIMARÃES. 2009. p. 93). Não se discute uma mudança efetiva de pressupostos na relação com a natureza, pelo contrário, a natureza é incorporada na dimensão econômica, ficando seu controle a cargo dos dispositivos de mercado e da legislação. (SILVA, 2013. p. 233). Havendo a simplificação dos problemas ambientais, derivados de uma ciência parcializada, com resultados desconexos da realidade e do todo.

Discutir, repensar valores e ideologias para que sociedades sejam sustentáveis, são encargos intransferíveis que os docentes e a sociedade precisam assumir rumo a um conhecimento crítico, que descubra as reais formas de organização política da vida e que se estabeleça em novas bases de cooperação. Uma educação ambiental crítica, emancipadora e transformadora de realidades, para além do desenvolvimento sustentável, se não este, será responsável por respostas que não pode dar e soluções que não pode encontrar. 


\section{REFERÊNCIAS}

CAMARGO, A. L. B. Desenvolvimento sustentável: Dimensões e desafios. Campinas: Papirus; 2003.

COSTA, F. A. As ciências, o uso de recursos naturais na Amazônia e a noção de desenvolvimento sustentável: por uma interdisciplinaridade ampla.In: VIEIRA, C. G. [et al] Diversidade Biológica e Cultural da Amazônia. Belém: Museu Paraense Emílio Goeldi; 2009. p. 299-318.

DAL SOGLIO, F. K. Desenvolvimento, agricultura e agroecologia: qual o papel a ligação? In: GUERRA, D. A. D; WAQUIL, P. D. [Org.]Desenvolvimento rural sustentável no norte e sul do Brasil. Belém: Paka-Tatu, 2013. p. 197-226.

GUIMARÃES, M. Sustentabilidade e Educação Ambiental. In: CUNHA, S. B; GUERRA, A. J. T. A questão ambiental: diferentes abordagens. Rio de Janeiro: Bertrand Brasil; 2009. p. 81-105.

LIMA, D; POZZOBON, J. Amazônia Socioambiental: sustentabilidade ecológica e diversidade social. In: VIEIRA, C. G. [et al] Diversidade Biológica e Cultural da Amazônia. Belém: Museu Paraense Emílio Goeldi; 2009. p. 195-252.

LINDNER, E. L. Refletindo sobre o ambiente. In: LISBOA, C. P; KINDEL, E. A. I. [et al] Educação Ambiental: da teoria a prática. Porto Alegre: Mediação; 2012. p.13-20.

LOUREIRO, C.F.B. Sustentabilidade: Em defesa da educação ambiental no brasil. In: SILVA, M.L. Org. Políticas e práticas de educação ambiental na Amazônia: Das unidades de conservação aos grandes empreendimentos econômicos. Belém: UFPA; GEAM, 2014. p.13-27.

SILVA, L. M. R. O papel didático da crise da agricultura moderna para a compreensão da ascensão de um enfoque agroecológico. In: GUERRA, D. A. D; WAQUIL, P. D. [Org.]Desenvolvimento rural sustentável no norte e sul do Brasil. Belém: Paka-Tatu, 2013.p. 227248. 